\title{
Article \\ A Cross-Sectional Audit of Nutrition and Health Claims on Dairy Yoghurts in Supermarkets of the Illawarra Region of New South Wales, Australia
}

\author{
Sam-Reith S. Wadhwa ${ }^{1}$, Anne T. McMahon ${ }^{1}$ (D) and Elizabeth P. Neale ${ }^{1,2, *}$ \\ 1 School of Medicine, University of Wollongong, Wollongong, NSW 2522, Australia; \\ srsw710@uowmail.edu.au (S.-R.S.W.); amcmahon@uow.edu.au (A.T.M.) \\ 2 Illawarra Health and Medical Research Institute, University of Wollongong, Wollongong, NSW 2522, \\ Australia \\ * Correspondence: elizan@uow.edu.au; Tel.: +612-4221-5961
}

Citation: Wadhwa, S.-R.S.;

McMahon, A.T.; Neale, E.P. A

Cross-Sectional Audit of Nutrition and Health Claims on Dairy Yoghurts in Supermarkets of the Illawarra Region of New South Wales, Australia. Nutrients 2021, 13, 1835. https://doi.org/10.3390/nu13061835

Academic Editor: Dennis Savaiano

Received: 19 May 2021

Accepted: 25 May 2021

Published: 27 May 2021

Publisher's Note: MDPI stays neutral with regard to jurisdictional claims in published maps and institutional affiliations.

Copyright: (c) 2021 by the authors. Licensee MDPI, Basel, Switzerland. This article is an open access article distributed under the terms and conditions of the Creative Commons Attribution (CC BY) license (https:/ / creativecommons.org/licenses/by/ $4.0 /)$.

\begin{abstract}
Health and nutrition claims are used by consumers to guide purchasing decisions. In consequence, monitoring and evaluation of such claims to ensure they are accurate and transparent is required. The aim of this study was to investigate the use of nutrition and health claims on dairy-yoghurt products within select Australian supermarkets and assess their compliance with the revised Food Standards Code (FSC). Nutrition, health, and related claims on yoghurt products were assessed in a cross-sectional audit of five supermarkets in the Illawarra region of New South Wales. Claim prevalence, type, and compliance were assessed and products were compared against current rating measures. A total of $n=340$ dairy yoghurt products were identified. Most products $(97.9 \%)$ carried at least one nutrition and/or health claim, with nutrition-content claims $(93.9 \%)$ the most prevalent. Most products $(n=277)$ met the nutrient profiling scoring criterion; while $87.9 \%$ of products did not carry the health star rating. Almost all claims surveyed (97.4\%) were compliant with the FSC. Health and nutrition claims are highly prevalent across yoghurt categories, with the majority of these compliant with regulations. The ambiguity surrounding the wording and context of claims challenges researchers to investigate consumers' interpretations of health messaging within the food environment.
\end{abstract}

Keywords: food standards code; dairy yoghurts; nutrition claims; health claims; claim compliance; nutrition profiling; health star rating

\section{Introduction}

Health and nutrition claims are a key component of the food environment, utilised by food companies and manufacturers as a way of informing consumers and influencing purchasing behaviour [1,2]. These claims have been shown to have varying influences on a consumer's ability to navigate the food environment and make informed health choices [3-6]. As a major purchasing point for food products, supermarkets are a direct channel between consumers and their respective food environments [7-9], reinforcing the need for accurate and coherent health information within this space.

In Australia and New Zealand, health, nutrition, and related claims are regulated by the Food Standards Code (FSC) [10], specifically Standard 1.2.7, which outlines the types of claims that can be made and the conditions under which they can be made. Under Standard 1.2.7, three types of claims can be made: content claims, general-level health claims, and high-level health claims [10]. Furthermore, in order to make either general or high-level health claims, products must meet the nutrient profiling scoring criterion (NPSC) [11], which categorises foods according to their nutritional composition. Since the revision of the code in 2013 and its subsequent enforcement in 2016, investigation into compliance of food packaging claims in Australia has been limited [12]. While the code has enhanced the ability 
of manufacturers to promote ingredients and products such as fruit and vegetables [13], investigations into prominent supermarket items such as breakfast cereals [14], muesli bars [15], and ultra-processed foods [16] have found varying proportions of claims not compliant with the FSC. Such noncompliant claims can not only lead to legislative and production implications for food manufacturers, but also potentially mislead consumers' food practices and behaviours [6,7]. Given the differing levels of compliance observed, it is important that a range of food categories are investigated in order to quantify the use of nutrition and health claims across the food supply.

Yoghurt is a core dairy food and source of calcium contributing to bone and muscle health, as well as blood and hormonal function [17-21]. Despite these positive health implications, and correlations between health and nutrition claims on yoghurt packaging and heightened consumer desirability and purchasing behaviour [1], research into the quantity and compliance of health, nutrition, and related claims on yoghurts in Australia is limited, pre-dating the changes to the FSC [22,23]. This presents the potential for misinformation within the food environment, resulting in likely misguided consumer choices as well as diminishing the capacity of health professionals, such as dietitians, to decipher and convey product information effectively [24-26]. An updated investigation of nutrition and health claims made on yoghurt products and their compliance with regulations is therefore needed.

The aim of this study was to investigate the use of nutrition, health, and related claims on yoghurt products in Australian supermarkets, and assess the compliance of these products with the revised FSC.

\section{Materials and Methods}

This study involved a cross-sectional audit of nutrition and health claims made on yoghurt products available in supermarkets in the Illawarra region of New South Wales, Australia.

\subsection{Selection of Supermarkets}

Supermarkets were selected based on market share, socioeconomic status, and previous Illawarra supermarket audits [14,27]. The 2018 Supermarket and Fresh Food Currency Report by Roy Morgan indicated that the Woolworths Group (34.0\%), Coles Group (27.6\%), and Aldi (11.4\%) were the top three Australian supermarket chains in terms of market share [28]. As Woolworths currently holds the greatest share [28], three stores were selected (Unanderra, Bulli, and Shellharbour) for the audit. The location of stores was selected based on varying levels of socioeconomic status [29] and previous audits [14,27] in order to obtain equitable [30] and detailed data relating to yoghurt products in the region. Coles Wollongong and Aldi Wollongong were also selected for analysis due to their significant market share [28] and varied product selection [31,32].

\subsection{Pilot Study}

Prior to full data collection, a pilot study was conducted across two days in January 2020 to assess different data collection methods, and the approximate quantity of yoghurt products available in selected supermarkets. A list of yoghurt products was developed prior to the investigation using Coles' [33] and Woolworths' [34] online stores. The keywords "yoghurt" and "fermented dairy products" were searched in each of the online websites in order to develop a comprehensive product checklist prior to pilot data collection. In cases where duplicate items were found, only the Woolworths item was included, as it was the first store piloted. Additions were made to the checklist if products not included on the website were found during a physical review of the supermarket. As Aldi did not have an extensive online platform [31], it was excluded from the pilot study.

Coles Wollongong and Woolworths Unanderra were assessed during the pilot study, with approximately 310 different yoghurt products found between the stores. Due to Aldi's narrow product range and lack of preference for home-brand products [35] it was estimated 
that the chain had approximately 50 different yoghurt varieties in addition to those found in Coles and Woolworths. Items found during the pilot study included: yoghurt tubs and pods, yoghurt pouches, and dairy-free yoghurt varieties. From the investigation and assumptions, it was estimated that 330-380 different yoghurt products would be available for analysis.

\subsection{Data Collecion}

Following the pilot study, data collection for the supermarket audit took place over five days in February 2020. Letters were sent to each store manager prior to data collection informing them of the process to be undertaken within the store and the scope of the study. Permission was also sought on the day of data collection from the store manager and was granted.

For the purpose of the audit, yoghurt products were classified into 11 categories in accordance with the AUSNUT 2011-13 food and dietary supplement classification system for yoghurts [36], with an additional two categories ("children's yoghurt" and "yoghurt pouches") included after consultation with the research team and pilot findings (Table 1). Products that did not appear within the AUSNUT Classification System's yoghurt categories, such as frozen yoghurts and infant yoghurt/custards (defined as those aimed at children aged less than one year of age [37]) were excluded from analysis. In addition, as the focus of this research was on dairy yoghurt (as defined by AUSNUT 2011-13); nondairy-based yoghurt products such as coconut yoghurt were not included in this project. This aligns with the categorisation of these products as "milk substitutes" according to the AUSNUT classification system, and as a separate food group to yoghurt in the FSC [10]. Furthermore, items not available in analysed supermarket aisles, such as milk yoghurt (liquid consistency) and buttermilk yoghurt, were also excluded. Excluded items photographed during data collection were deleted prior to data analysis.

Table 1. Inclusion and exclusion list of analysed yoghurt products (based on AUSNUT 2011-13 categorisation).

\begin{tabular}{|c|c|}
\hline Included Products & Excluded Products \\
\hline $\begin{array}{l}\text { Yoghurt, natural, regular fat, and high fat ( }>4 \mathrm{~g} / 100 \mathrm{~g} \text { fat }) \\
\text { Yoghurt, natural, reduced fat } \\
\text { Yoghurt, natural, skim and nonfat } \\
\text { Yoghurt, flavoured or added fruit and / or cereal, high fat } \\
\text { ( }>4 \mathrm{~g} / 100 \mathrm{~g} \text { fat) } \\
\text { Yoghurt, flavoured or added fruit, full fat } \\
\text { Yoghurt, flavoured or added fruit with added cereal, full fat } \\
\text { Yoghurt, flavoured or added fruit, reduced fat } \\
\text { Yoghurt, flavoured or added fruit, low fat or skim, sugar } \\
\text { sweetened } \\
\text { Yoghurt, flavoured or added fruit, low fat, or skim, intense } \\
\text { sweetened } \\
\text { Yoghurt, added nutrients or other substances } \\
\text { Yoghurt, unspecified fat } \\
\text { Children's yoghurt } \\
\text { Yoghurt pouches }\end{array}$ & $\begin{array}{c}\text { Frozen yoghurt (desserts) } \\
\text { Yoghurt-based Confectionary } \\
\text { Infant Yoghurts/Custards } \\
\text { Nondairy-based yoghurt products } \\
\text { Milk yoghurt (liquid consistency) } \\
\text { Buttermilk yoghurt }\end{array}$ \\
\hline
\end{tabular}

Data was collected during the audit by taking photographs of the front, back, sides, top, and bottom of all eligible yoghurt products within the "dairy", and "yoghurt" aisles of each supermarket. All eligible yoghurt products available at the time of data collection were audited. Information collected from each yoghurt product included brand name and variety, price, nutrition information panel (NIP) (serving size, energy, protein, fibre, sodium, total fat, saturated fat, sugar, and any other nutrients present on the panel), ingredients list (percentage of fruit, vegetables, nuts and legumes (FVNL), natural and 
artificial colours, flavours, preservatives, emulsifiers, sweeteners), and the health star rating (HSR) (if available).

Health, nutrition, and related claims were also collected for each yoghurt product including the number, wording, and type of claim (including nutrition content, highlevel health, general-level health, therapeutic, or any other claim which did not fit into the aforementioned category). To ensure that all data was accurately obtained during collection, a cross-check of $10 \%$ of the items photographed (e.g., checking the researcher's phone gallery to ensure that photographs of the products had all the necessary information for analysis) [38]. In cases where products were available in multiple sizes, the largest size was included, as it is more likely to carry the greatest number of claims [39]. Variety yoghurt packs with different flavours were treated as individual products, as their nutritional composition and claims may differ between flavours. All duplicate items were deleted prior to data analysis.

After data collection, all data was entered into a Microsoft Excel 365 v 16.0 (Microsoft Corporation, Santa Rosa, California, United States, 2017) spreadsheet for analysis.

\subsection{Calculation of Nutrient Profiling Scoring Criterion (NPSC) and Health Star Rating (HSR)}

Following completion of the audit, the information collected during the audit was used to apply the nutrient profiling scoring criterion (NPSC) for all analysed yoghurt products, in order to determine which products were eligible to carry a health claim [11]. The food properties required for the NPSC were obtained from the NIP of each product, including energy, total and saturated fat, sugar, sodium, protein, fibre, and percentage of fruit, vegetables, nuts and legumes (FVNL) [11].

The NPSC allocates food properties into two categories, baseline points (B) and modifying points (V Points). Baseline points include energy, saturated fat, sugar, and sodium of the product per $100 \mathrm{~g}$, while modifying points consist of the product's FVNL percentage, protein $(\mathrm{P})$, and fibre $(\mathrm{F})$ per $100 \mathrm{~g}$. The final score is calculated by subtracting the total modifying points (FVNL $+\mathrm{P}+\mathrm{F})$ from baseline points; baseline points-((FVNL) $+(\mathrm{P})+(\mathrm{F}))[11]$. The final value is then utilised to determine whether or not a product is eligible to carry health claims.

The value used to indicate whether a product meets the NPSC varies across food and beverage categories. Yoghurt, and yoghurt-containing products must achieve a score less than four to meet the NPSC and be eligible to carry a general or high-level health claim [11]. In the current study, while most components required for the NPSC were obtained from the NIP and ingredients list, certain properties such as fibre and saturated fat content were not available on some of the audited products. In such instances, the contents were estimated based on averages of similar yoghurt products containing the food property on the NIP (Supplementary Table S1). Finally, in cases where estimations of nutrient content appeared on a product's NIP such as " $<1$ g" or " $<0.1$ g" the value was assumed to be half of that specified, for instance if the NIP stated "Fibre: $<1 \mathrm{~g}$ ", it was treated as $0.5 \mathrm{~g}$. Due to the low amount of these nutrients present in the products, it should be noted that this estimation would not affect the NPSC calculated.

In cases where FVNL percentages were not present on yoghurt packaging, estimates were made based on the ingredient list (which must be listed in descending order according to weight) [40] and similar yoghurt products containing similar ingredient/s. However, it should be noted that in order for a product to be eligible for FVNL points it must contain either $25 \%$ or more of concentrated fruit or vegetables; more than $40 \%$ nonconcentrated FVNL; or a mixture of more than $40 \%$ of nonconcentrated FVNL and concentrated fruit or vegetables [41]. In terms of yoghurt products analysed, concentrated fruit or vegetable content was the most common FVNL criteria assessed, with the majority of products not meeting the cut-off required, suggesting that the imputation of the amount of FVNL would have minimal effect on the NPSC calculated.

The HSR was also calculated for all yoghurt products. Utilising the nutrition composition per $100 \mathrm{~g}$, the HSR allocates points for energy, saturated fat, sodium, and total sugar 
contents (risk factors for chronic disease), as well as FVNL content, protein, and fibre [42]. In addition to calculating the HSR for all products, whether a product listed the HSR on its packaging was also noted.

\subsection{Claim Type and Classification}

\subsubsection{Included Claims}

The FSC defines "claims" as "an express or implied statement, representation, design or information in relation to a food or a property of food" [10]. In consequence, the formatting of claims (images, testimonials, or text) on food packaging was considered negligible and all claims were included in this analysis, regardless of their format.

Claims identified in the audit for analysis were classified in accordance with the FSC, as nutrition-content claims (e.g., "good source of calcium"), general-level health claims (e.g., "probiotics assist with digestion"), high-level health claims (e.g., "high calcium assists in prevention of osteoporosis"), or therapeutic claims (e.g., "a diet low in sodium could cure high blood pressure") [10] (Table 2). General health claims that were not pre-approved under Standard 1.2.7, were categorised as self-substantiated claims, in line with the FSC [43]. The HSR, although not outlined in Standard 1.2.7 [10], was also included in analysis due to its increasing prevalence and awareness amongst consumers [44].

Table 2. Inclusion and exclusion list of analysed claims.

\begin{tabular}{cc}
\hline Included Claims & Excluded Claims \\
\hline Nutrition content claims & Puffery claims \\
$\begin{array}{c}\text { General-level health claims (pre-approved and self-substantiated) } \\
\text { High-level health claims } \\
\text { Therapeutic claims }\end{array}$ & Endorsements \\
\hline
\end{tabular}

\subsubsection{Excluded Claims}

Puffery claims (e.g., "the goodness of milk", "natural", "organic") were excluded from analysis as they were not defined within the FSC (Figure S1). Additionally, endorsements (e.g., "used by the Australian Olympic Team"), while outlined by the FSC, were not included in analysis as they are not considered to constitute a nutrition and health claim per se (Table 2).

\subsection{Claim Compliance}

All claims were evaluated for compliance against the FSC and Schedule Four [10]. This included ensuring that products met the NPSC (in the case of health claims) [11] and nutrient quantity levels when claims were related to certain properties of food [45]. For example, a yoghurt product making a claim regarding it being a "good source of protein" must contain at least $10 \mathrm{~g}$ of protein per serving. Self-substantiated general-level health claims were checked against the Food Standards Australia New Zealand (FSANZ) Notified Food-Health Relationships database [43] to determine if they had been notified to FSANZ in line with FSC requirements. The number, type, and wording of claims was determined. In line with the requirements of the FSC, in order for a comparative claim (for example " $25 \%$ less fat than our regular vanilla yoghurt") to be made by a product, it must have specified the "reference food" [10]; if not, the claim was considered noncompliant. The calculated and packaged HSR (if applicable) for each product was also determined to investigate the number of products containing the HSR and whether the calculated values matched those on the yoghurt products.

\subsection{Other Specifications and Assumptions}

During the process of claim classification and assessing claim compliance, professional judgement was required in some cases to categorise claims and determine their compliance. For example, in cases where claim conditions were not specified by the FSC (for example content claims relating to probiotics or live cultures [45]), claim compliance was assessed 
utilising criteria outlined in Clause 13 of Standard 1.2.7, which states, "nutrition-content claims can be made about a food property not mentioned in Schedule Four, although the claim may only state if the product does or does not contain the food property, or if the food contains a specified amount of the food property, or a combination of both" [10]. In consequence, yoghurt products including claims on such food properties were only assessed as compliant if they contained permitted statements (e.g., "three probiotics", "contains live yoghurt cultures") set out by Clause 13 of Standard 1.2.7.

Throughout the study, words used to describe properties of yoghurt products such as "rich" and "good" were classified as a "good source of (nutrient)" in claim analysis. Nutrition-content claims that were not specifically referred to in the FSC such as "gelatinefree" or "no stevia" were classified as "other". Claims containing a quantity without specifying individual nutrients such as "contains nine essential amino acids" were treated as one nutrition-content claim and classified as "other". In addition, claims worded as, e.g., "low-fat yoghurt" were evaluated to the same criteria as "low fat" claims. Claims relating to probiotics were classified as "live cultures", and "thickeners", "sweeteners", and "food acids" were classified as claims relating to artificial colours/flavours/preservatives.

\subsection{Data Quality}

After data analysis, a second researcher (EN) conducted a random audit of a 10\% subsample of yoghurt products ( $n=34$ products). This involved independently calculating the NPSC and HSR of each product as well as the number, type, and wording of claims on the products sampled, and determining the compliance of these claims.

\subsection{Statstical Analysis}

Data was analysed and summarised using Microsoft Excel 365 v 16.0 (Microsoft, 2017). The total number of products surveyed and those carrying claims was determined, as well the average and total number of products from each yoghurt category. Data was also analysed by claim type, with the number and percentage of claims per yoghurt category assessed. Further classification of claim type and yoghurt category was undertaken according to each product's compliance with the NPSC, to investigate which yoghurt products were able to make health claims, as well as compliance of claims with the NPSC. The presence of the HSR on packaging was classified according to different yoghurt categories, with the average calculated HSR also determined. The compliance of claims was analysed by evaluating the proportion of claims compliant per yoghurt category, claim type (FSC) and FSANZ NPSC.

\section{Results}

Overall, 340 products were surveyed across five supermarkets in the Illawarra region with a total of 1680 health, nutrition, and related claims identified across these products.

\subsection{Claim Prevalence}

During the process of claim classification and assessing claim compliance, professional judgement was required in some cases to categorise claims and determine their compliance. Of the 13 yoghurt categories eligible for inclusion (Table 1) yoghurt products from 10 categories were identified during the audit. Products under the classification of "yoghurt, unspecified fat", "yoghurt, added nutrients or other substances", and "yoghurt, flavoured or added fruit with added cereal, full fat" were not found in the selected supermarkets during the audit.

Table 3 highlights the prevalence of products and claims found across each yoghurt category $(n=10)$. Of the total products surveyed, yoghurt products classified as "yoghurt pouches" ( $n=91,26.8 \%)$, "yoghurt, flavoured or added fruit and/or cereal, high fat (>4 g/100 g fat)" ( $n=72,21.2 \%)$, and "yoghurt, flavoured or added fruit, reduced fat" $(n=58,17.1 \%)$ had the highest prevalence across the five supermarkets. The "yoghurt, 
natural, reduced fat", category had the lowest proportion of products analysed ( $n=6$, $1.7 \%)$.

Table 3. Number and proportion of claims prevalent across yoghurt categories.

\begin{tabular}{|c|c|c|c|c|}
\hline \multirow[t]{2}{*}{ Yoghurt Category } & \multicolumn{2}{|c|}{ Product Category } & \multicolumn{2}{|r|}{ Products Carrying Claims } \\
\hline & $(n)$ & $\begin{array}{c}\% \text { of Total Products } \\
\text { Surveyed }\end{array}$ & $(n)$ & $\begin{array}{c}\% \text { of Products per Category } \\
\text { Carrying Claims }\end{array}$ \\
\hline $\begin{array}{l}\text { Yoghurt, natural, regular fat, } \\
\text { and high fat (>4 g/100 g fat) }\end{array}$ & 30 & $8.8 \%$ & 30 & $100.0 \%$ \\
\hline Yoghurt, natural, reduced fat & 6 & $1.7 \%$ & 6 & $100.0 \%$ \\
\hline $\begin{array}{c}\text { Yoghurt, natural, skim and } \\
\text { nonfat }\end{array}$ & 10 & $2.9 \%$ & 10 & $100.0 \%$ \\
\hline $\begin{array}{l}\text { Yoghurt, flavoured or added } \\
\text { fruit and/or cereal, high fat } \\
\qquad(>4 \mathrm{~g} / 100 \mathrm{~g} \text { fat })\end{array}$ & 72 & $21.2 \%$ & 65 & $90.3 \%$ \\
\hline $\begin{array}{l}\text { Yoghurt, flavoured or added } \\
\text { fruit, full fat }\end{array}$ & 30 & $8.8 \%$ & 30 & $100.0 \%$ \\
\hline $\begin{array}{l}\text { Yoghurt, flavoured or added } \\
\text { fruit, reduced fat }\end{array}$ & 58 & $17.1 \%$ & 58 & $100.0 \%$ \\
\hline $\begin{array}{l}\text { Yoghurt, flavoured or added } \\
\text { fruit, low fat or skim, sugar } \\
\text { sweetened }\end{array}$ & 7 & $2.1 \%$ & 7 & $100.0 \%$ \\
\hline $\begin{array}{l}\text { Yoghurt, flavoured or added } \\
\text { fruit, low fat, or skim, } \\
\text { intense sweetened }\end{array}$ & 28 & $8.2 \%$ & 28 & $100.0 \%$ \\
\hline Children's yoghurt & 8 & $2.4 \%$ & 8 & $100.0 \%$ \\
\hline Yoghurt pouches & 91 & $26.8 \%$ & 91 & $100.0 \%$ \\
\hline Overall & 340 & $100.0 \%$ & 333 & n/a \\
\hline
\end{tabular}

Regarding claim prevalence, 333 of the 340 products analysed contained at least one health, nutrition, and/or related claim $(97.9 \%)$. The products not carrying any claim $(n=7)$ were all found in the "yoghurt, flavoured or added fruit and/or cereal, high fat (>4 g/100 g fat)" category, with all products in the remaining nine yoghurt categories carrying at least one claim (Table 3).

Table 4 notes that of the products carrying health and/or nutrition claims $(n=333)$, the average number of claims per product was 5.0, with yoghurt products in the "yoghurt, flavoured or added fruit, low fat or skim, sugar sweetened" category having the highest average number of claims per product (7.7), and products in the "yoghurt, flavoured or added fruit and/or cereal, high fat (>4 g/100 g fat)" category having the lowest (2.6). The yoghurt categories which carried the greatest proportion of health and/or nutrition claims were "yoghurt pouches" $(n=565,33.6 \%)$, "yoghurt, flavoured or added fruit, reduced fat" ( $n=265,15.8 \%)$, and "yoghurt, flavoured or added fruit and/or cereal, high fat (>4 g/100 g fat)" ( $n=169,10.1 \%$ ) (Table 4$)$. For products carrying claims, the maximum number of total claims found in any one product was 15 , and the minimum was one. 
Table 4. Total and average numbers of health, nutrition, and related claims per yoghurt category.

\begin{tabular}{cccc}
\hline Yoghurt Category & \multicolumn{2}{c}{ Total Number of Claims } & Average Claims per Product \\
\hline & $(n)$ & \% of All Claims & $(n)$ \\
\hline Yoghurt, natural, regular fat, and high fat & 167 & $9.9 \%$ & 5.6 \\
$\begin{array}{c}(>4 \text { g } / 100 \text { g fat) } \\
\text { Yoghurt, natural, reduced fat }\end{array}$ & 30 & $1.8 \%$ & 5.0 \\
$\begin{array}{c}\text { Yoghurt, natural, skim and nonfat } \\
\text { Yoghurt, flavoured or added fruit and/or } \\
\text { cereal, high fat }(>4 \text { g/100 g fat) }\end{array}$ & 66 & $3.9 \%$ & 6.6 \\
$\begin{array}{c}\text { Yoghurt, flavoured or added fruit, } \\
\text { full fat }\end{array}$ & 169 & $10.1 \%$ & 2.6 \\
$\begin{array}{c}\text { Yoghurt, flavoured or added fruit, } \\
\text { reduced fat }\end{array}$ & 265 & $9.6 \%$ & 5.4 \\
$\begin{array}{c}\text { Yoghurt, flavoured or added fruit, low fat } \\
\text { or skim, sugar sweetened }\end{array}$ & 52 & $15.8 \%$ & 4.6 \\
$\begin{array}{c}\text { Yoghurt, flavoured or added fruit, low } \\
\text { fat, or skim, intense sweetened }\end{array}$ & 184 & $3.1 \%$ & 7.7 \\
$\quad \begin{array}{c}\text { Children's yoghurt } \\
\text { Yoghurt pouches }\end{array}$ & 21 & $10.9 \%$ & 6.6 \\
Overall & 565 & $33.6 \%$ & 2.6 \\
\hline
\end{tabular}

\subsection{Claim Type and Classification}

Of all the health and nutrition claims found $(n=1680), 1577(93.9 \%)$ were nutritioncontent claims and 103 (6.1\%) were general-level health claims (Table 5). No high-level health claims were identified during the audit. Table 5 identifies the prevalence of the various claim types in the yoghurt categories $(n=10)$ analysed during the audit. The highest proportion of nutrition-content claims per yoghurt category were found in the "children's yoghurt" ( $n=21,100.0 \%)$, "yoghurt, natural, skim, and nonfat" $(n=66,100.0 \%)$, and "yoghurt, flavoured or added fruit, low fat or skim, sugar sweetened" $(n=52,100.0 \%)$ categories, whilst products in the "yoghurt, flavoured or added fruit and/or cereal, high fat $(>4 \mathrm{~g} / 100 \mathrm{~g}$ fat)" category $(n=169)$ contained the lowest proportion of general-level health claims $(n=3,1.8 \%)$ of categories that contained at least one of these claims.

Table 5. Prevalence of claim types per yoghurt category.

\begin{tabular}{|c|c|c|c|c|c|}
\hline \multirow[t]{2}{*}{ Yoghurt Category } & \multicolumn{2}{|c|}{ Nutrition-Content Claims } & \multicolumn{2}{|c|}{ General-Level Health Claims } & \multirow[t]{2}{*}{ Total } \\
\hline & (n) & $\begin{array}{l}\% \text { of Claims per } \\
\text { Yoghurt Category }\end{array}$ & (n) & $\begin{array}{l}\% \text { of Claims per } \\
\text { Yoghurt Category }\end{array}$ & \\
\hline $\begin{array}{l}\text { Yoghurt, natural, regular fat, } \\
\text { and high fat (>4 g/100 g fat) }\end{array}$ & 157 & $94.0 \%$ & 10 & $6.0 \%$ & 167 \\
\hline Yoghurt, natural, reduced fat & 28 & $93.3 \%$ & 2 & $6.7 \%$ & 30 \\
\hline $\begin{array}{c}\text { Yoghurt, natural, skim and } \\
\text { nonfat }\end{array}$ & 66 & $100.0 \%$ & 0 & $0 \%$ & 66 \\
\hline $\begin{array}{l}\text { Yoghurt, flavoured or added } \\
\text { fruit and/or cereal, high fat } \\
\qquad>4 \mathrm{~g} / 100 \mathrm{~g} \text { fat })\end{array}$ & 166 & $98.2 \%$ & 3 & $1.8 \%$ & 169 \\
\hline $\begin{array}{l}\text { Yoghurt, flavoured or added } \\
\text { fruit, full fat }\end{array}$ & 149 & $92.6 \%$ & 12 & $7.4 \%$ & 161 \\
\hline $\begin{array}{l}\text { Yoghurt, flavoured or added } \\
\text { fruit, reduced fat }\end{array}$ & 255 & $96.2 \%$ & 10 & $3.8 \%$ & 265 \\
\hline $\begin{array}{l}\text { Yoghurt, flavoured or added } \\
\text { fruit, low fat or skim, sugar } \\
\text { sweetened }\end{array}$ & 52 & $100.0 \%$ & 0 & $0 \%$ & 52 \\
\hline $\begin{array}{l}\text { Yoghurt, flavoured or added } \\
\text { fruit, low fat, or skim, intense } \\
\text { sweetened }\end{array}$ & 171 & $92.9 \%$ & 13 & $7.1 \%$ & 184 \\
\hline Children's yoghurt & 21 & $100.0 \%$ & 0 & $0 \%$ & 21 \\
\hline Yoghurt pouches & 512 & $90.6 \%$ & 53 & $9.4 \%$ & 565 \\
\hline Overall & 1577 & $93.9 \%$ & 103 & $6.1 \%$ & 1680 \\
\hline
\end{tabular}

The five most common types of nutrition content and general-level health claims assessed in the audit are shown in Table 6. The most common nutrition-content claim 
( $n=1577)$ identified was "no artificial colours/flavours/preservatives" $(n=414,26.3 \%)$, followed by claims classed as "other' (e.g., "gelatine free", "no powders") $(n=194,12.3 \%)$ and "live yoghurt cultures" $(n=191,12.1 \%)$. Of the 103 general-level health claims assessed, 29 were classified as "self-substantiated" ( $n=29,28.2 \%)$, with the majority of these claims relating to digestive health and wellbeing, $23(22.3 \%)$ were classified as "calcium" and 20 $(19.4 \%)$ were related to "protein". General-level health claims classified as "not specified" made up 5.8\% (e.g.,"Healthy snack that will give you the right fuel to keep going"), which related to claims that did not fall into any one specific general-level claim condition outlined in the FSC. Claims that made up less than six percent of the total nutrition-content claims (e.g., "lactose free" and "source of dietary fibre") and less than five percent of general-level health claims (e.g., "calcium and vitamin D for strong bones and teeth") were grouped as "less common claims".

Table 6. Most popular health, nutrition, or related claims per claim type.

\begin{tabular}{|c|c|c|c|c|c|}
\hline \multicolumn{3}{|c|}{ Nutrition-Content Claims } & \multicolumn{3}{|c|}{ General-Level Health Claims } \\
\hline & $(n)$ & $\%$ of Claim Type & & $(n)$ & $\%$ of Claim Type \\
\hline $\begin{array}{l}\text { Content: no artificial } \\
\text { colours/flavours/ } \\
\text { preservatives }\end{array}$ & 414 & $26.3 \%$ & $\begin{array}{c}\text { General: } \\
\text { self-substantiated }\end{array}$ & 29 & $28.2 \%$ \\
\hline Other & 194 & $12.3 \%$ & General: calcium & 23 & $22.3 \%$ \\
\hline $\begin{array}{l}\text { Content: live yoghurt } \\
\text { cultures }\end{array}$ & 191 & $12.1 \%$ & General: protein & 20 & $19.4 \%$ \\
\hline Content: no added sugar & 125 & $7.9 \%$ & $\begin{array}{l}\text { General: live yoghurt } \\
\text { cultures }\end{array}$ & 11 & $10.7 \%$ \\
\hline \multirow{3}{*}{$\begin{array}{l}\text { Content: gluten free } \\
\text { Content: source of } \\
\text { calcium } \\
\text { Less common claims }\end{array}$} & 124 & $7.8 \%$ & General: vitamin B12 & 6 & $5.8 \%$ \\
\hline & 102 & $6.5 \%$ & $\begin{array}{c}\text { General: not } \\
\text { specified }\end{array}$ & 6 & $5.8 \%$ \\
\hline & 427 & $27.1 \%$ & Less common claims & 8 & $7.8 \%$ \\
\hline Total & 1577 & & & 103 & \\
\hline
\end{tabular}

\subsection{Claim Classification according to FSANZ NPSC and the Health Star Rating}

Of the 340 products analysed, $277(81.5 \%)$ met the NPSC and were therefore eligible to make a health claim while 63 products $(18.5 \%)$ did not meet the NPSC and cannot make a health claim under the FSC (however it should be noted that these products are still able to make nutrition-content claims under the FSC regulations). All products $(100.0 \%)$ in six out of 10 yoghurt categories analysed met the NPSC (Table 7). Of the other categories, the "yoghurt, flavoured or added fruit and/or cereal, high fat (>4 g/100 g fat)" category contained the highest proportion $(n=52,72.2 \%$ ) of products that did not meet the NPSC.

In addition to examining the proportion of overall products which met the NPSC, individual claims $(n=1680)$ were also explored according to whether the product met the NPSC. According to the FSC, nutrition-content claims $(n=1577)$ are allowed on food packaging regardless of whether the product meets the NPSC, while general-level health claims $(n=103)$ and high-level health claims (none found during analysis) can only be made on products that meet the NPSC.

Overall, of the 1680 nutrition content and general-level health claims analysed, 1531 $(91.1 \%)$ were on products that met the NPSC. From the nutrition-content claims analysed ( $n=1577), 1429(90.6 \%)$ were on products that met the NPSC, while $148(9.4 \%)$ were on products that did not. In regard to general-level health claims $(n=103), 102$ claims $(99.0 \%)$ were on products eligible to carry health claims, while only one general-level health claim $(1.0 \%)$ was on a yoghurt product that did not meet the NPSC, contradictory to violating the FSC regarding the conditions for health-related claims to be made on products.

The HSR was calculated for all products $(n=340)$ regardless of whether it was available on their packaging. All ratings appearing on yoghurt products matched the calculated HSR for that product. The average calculated HSR was 3.5, with 191 products $(56.2 \%)$ above the average, and $149(43.8 \%)$ products below. Of the products above the calculated HSR average $(n=191), 26(13.6 \%)$ products carried the HSR on their packaging, while 15 of 
the 149 products (10.1\%) below the average carried the HSR on their packaging. Table 8 details the products displaying the HSR on their packaging by yoghurt category. Of the 340 products analysed, 299 (87.9\%) did not contain the HSR on the product packaging, while $41(12.1 \%)$ products did contain the HSR. Nine out of the 10 yoghurt categories had at least one product that carried the HSR, with the "yoghurt, flavoured or added fruit, reduced fat" category containing the highest number of products $(n=16)$ carrying the HSR on packaging. The "yoghurt, flavoured or added fruit, low fat or skim, sugar sweetened" category did not contain any products with the HSR on their packaging, with all categories $(n=10)$ containing a higher proportion of products not carrying the HSR.

Table 7. Proportion of products that met the NPSC per yoghurt category.

\begin{tabular}{|c|c|c|c|c|c|}
\hline \multirow[t]{2}{*}{ Yoghurt Category } & \multicolumn{2}{|c|}{ Meets the NPSC } & \multicolumn{2}{|c|}{ Does not Meet NPSC } & \multirow[t]{2}{*}{ Tota } \\
\hline & $(n)$ & $\begin{array}{l}\% \text { of Products that } \\
\text { met NPSC }\end{array}$ & (n) & $\begin{array}{l}\% \text { of Products that did } \\
\text { not Meet the NPSC }\end{array}$ & \\
\hline $\begin{array}{l}\text { Yoghurt, natural, regular fat, } \\
\text { and high fat ( }>4 \mathrm{~g} / 100 \mathrm{~g} \text { fat) }\end{array}$ & 21 & $70.0 \%$ & 9 & $30.0 \%$ & 30 \\
\hline Yoghurt, natural, reduced fat & 6 & $100.0 \%$ & 0 & $0 \%$ & 6 \\
\hline $\begin{array}{c}\text { Yoghurt, natural, skim and } \\
\text { nonfat }\end{array}$ & 10 & $100.0 \%$ & 0 & $0 \%$ & 10 \\
\hline $\begin{array}{l}\text { Yoghurt, flavoured or added } \\
\text { fruit and / or cereal, high fat } \\
\qquad>4 \mathrm{~g} / 100 \mathrm{~g} \text { fat })\end{array}$ & 20 & $27.8 \%$ & 52 & $72.2 \%$ & 72 \\
\hline $\begin{array}{l}\text { Yoghurt, flavoured or added } \\
\text { fruit, full fat }\end{array}$ & 29 & $96.7 \%$ & 1 & $3.3 \%$ & 30 \\
\hline $\begin{array}{l}\text { Yoghurt, flavoured or added } \\
\text { fruit, reduced fat }\end{array}$ & 58 & $100.0 \%$ & 0 & $0 \%$ & 58 \\
\hline $\begin{array}{l}\text { Yoghurt, flavoured or added } \\
\text { fruit, low fat or skim, sugar } \\
\text { sweetened }\end{array}$ & 7 & $100.0 \%$ & 0 & $0 \%$ & 7 \\
\hline $\begin{array}{l}\text { Yoghurt, flavoured or added } \\
\text { fruit, low fat, or skim, intense } \\
\text { sweetened }\end{array}$ & 28 & $100.0 \%$ & 0 & $0 \%$ & 28 \\
\hline Children's yoghurt & 8 & $100.0 \%$ & 0 & $0 \%$ & 8 \\
\hline Yoghurt pouches & 90 & $98.9 \%$ & 1 & $1.1 \%$ & 91 \\
\hline Overall & 277 & $81.5 \%$ & 63 & $18.5 \%$ & 340 \\
\hline
\end{tabular}

Table 8. Number of yoghurt products carrying the HSR per yoghurt category.

\begin{tabular}{|c|c|c|c|c|c|}
\hline \multirow[t]{2}{*}{ Yoghurt Category } & \multicolumn{4}{|c|}{ HSR on Packaging } & Total \\
\hline & $(n)$ & $\begin{array}{c}\% \text { of Yoghurt Category } \\
\text { that Carried HSR on } \\
\text { Packaging }\end{array}$ & (n) & $\begin{array}{l}\% \text { of Yoghurt Category } \\
\text { that did not carry HSR } \\
\text { on Packaging }\end{array}$ & \\
\hline $\begin{array}{l}\text { Yoghurt, natural, regular fat, } \\
\text { and high fat ( }>4 \mathrm{~g} / 100 \mathrm{~g} \text { fat) }\end{array}$ & 4 & $13.3 \%$ & 26 & $86.7 \%$ & 30 \\
\hline Yoghurt, natural, reduced fat & 2 & $33.3 \%$ & 4 & $66.7 \%$ & 6 \\
\hline $\begin{array}{c}\text { Yoghurt, natural, skim and } \\
\text { nonfat }\end{array}$ & 1 & $10.0 \%$ & 9 & $90.0 \%$ & 10 \\
\hline $\begin{array}{l}\text { Yoghurt, flavoured or added } \\
\text { fruit and/or cereal, high fat } \\
\qquad(>4 \mathrm{~g} / 100 \mathrm{~g} \text { fat })\end{array}$ & 1 & $1.4 \%$ & 71 & $98.6 \%$ & 72 \\
\hline $\begin{array}{l}\text { Yoghurt, flavoured or added } \\
\text { fruit, full fat }\end{array}$ & 1 & $3.3 \%$ & 29 & $96.7 \%$ & 30 \\
\hline $\begin{array}{l}\text { Yoghurt, flavoured or added } \\
\text { fruit, reduced fat }\end{array}$ & 16 & $27.6 \%$ & 42 & $72.4 \%$ & 58 \\
\hline $\begin{array}{l}\text { Yoghurt, flavoured or added } \\
\text { fruit, low fat or skim, sugar } \\
\text { sweetened }\end{array}$ & 0 & $0 \%$ & 7 & $100.0 \%$ & 7 \\
\hline $\begin{array}{l}\text { Yoghurt, flavoured or added } \\
\text { fruit, low fat, or skim, intense } \\
\text { sweetened }\end{array}$ & 6 & $21.4 \%$ & 22 & $78.6 \%$ & 28 \\
\hline Children's yoghurt & 3 & $37.5 \%$ & 5 & $62.5 \%$ & 8 \\
\hline Yoghurt pouches & 7 & $7.7 \%$ & 84 & $92.3 \%$ & 91 \\
\hline Overall & 41 & $12.1 \%$ & 299 & $87.9 \%$ & 340 \\
\hline
\end{tabular}




\subsection{Claim Compliance}

Of the 1680 claims assessed for claim compliance, 1637 (97.4\%) were compliant with the FSC, while 43 claims (2.6\%) were not compliant (Table 9). When considered for the 340 products surveyed during the audit, this equated to 297 (87.4\%) compliant products (i.e., they contained no noncompliant claims) and $43(12.6 \%)$ noncompliant products (i.e., they contained at least one noncompliant claim). A total of nine out of 10 yoghurt categories assessed contained at least one noncompliant claim; however, all categories had a higher proportion of compliant claims. All claims on products in the "yoghurt, natural, reduced fat" category $(n=30)$ were compliant with the code. The "children's yoghurt" category had the highest proportion of noncompliant claims $(n=2,9.5 \%)$, with the "yoghurt, flavoured or added fruit, full fat" category also carrying a substantial proportion of noncompliant claims $(n=13,8.1 \%)$.

Table 9. Compliance of health, nutrition, and related claims per yoghurt category.

\begin{tabular}{|c|c|c|c|c|c|}
\hline Yoghurt Category & & Compliant & & Noncompliant & Total \\
\hline & $(n)$ & $\begin{array}{l}\text { \% of Compliant } \\
\text { Claims in Each } \\
\text { Yoghurt Category }\end{array}$ & $(n)$ & $\begin{array}{l}\text { \% of Noncompliant } \\
\text { Claims in Each } \\
\text { Yoghurt Category }\end{array}$ & \\
\hline $\begin{array}{l}\text { Yoghurt, natural, regular fat, } \\
\text { and high fat ( }>4 \mathrm{~g} / 100 \mathrm{~g} \text { fat })\end{array}$ & 165 & $98.8 \%$ & 2 & $1.2 \%$ & 167 \\
\hline Yoghurt, natural, reduced fat & 30 & $100.0 \%$ & 0 & $0 \%$ & 30 \\
\hline $\begin{array}{c}\text { Yoghurt, natural, skim and } \\
\text { nonfat }\end{array}$ & 65 & $98.5 \%$ & 1 & $1.5 \%$ & 66 \\
\hline $\begin{array}{l}\text { Yoghurt, flavoured or added } \\
\text { fruit and / or cereal, high fat } \\
\qquad(>4 \mathrm{~g} / 100 \mathrm{~g} \text { fat })\end{array}$ & 164 & $97.0 \%$ & 5 & $3.0 \%$ & 169 \\
\hline $\begin{array}{l}\text { Yoghurt, flavoured or added } \\
\text { fruit, full fat }\end{array}$ & 148 & $91.9 \%$ & 13 & $8.1 \%$ & 161 \\
\hline $\begin{array}{l}\text { Yoghurt, flavoured or added } \\
\text { fruit, reduced fat }\end{array}$ & 263 & $99.2 \%$ & 2 & $0.8 \%$ & 265 \\
\hline $\begin{array}{l}\text { Yoghurt, flavoured or added } \\
\text { fruit, low fat or skim, sugar } \\
\text { sweetened }\end{array}$ & 50 & $96.2 \%$ & 2 & $3.8 \%$ & 52 \\
\hline $\begin{array}{l}\text { Yoghurt, flavoured or added } \\
\text { fruit, low fat, or skim, intense } \\
\text { sweetened }\end{array}$ & 179 & $97.3 \%$ & 5 & $2.7 \%$ & 184 \\
\hline Children's yoghurt & 19 & $90.5 \%$ & 2 & $9.5 \%$ & 21 \\
\hline Yoghurt pouches & 554 & $98.1 \%$ & 11 & $1.9 \%$ & 565 \\
\hline Overall & 1637 & $97.4 \%$ & 43 & $2.6 \%$ & 1680 \\
\hline
\end{tabular}

Of all the nutrition-content claims ( $n=1577), 1543(97.8 \%)$ were compliant with the FSC, while $34(2.2 \%)$ were not compliant with the FSC. Specific nutrition-content claims with the highest proportion of noncompliance included, "low fat" ( $n=14,41.2 \%$,), and "reduced/light sugar" ( $n=12,35.3 \%)$, as they did not meet the quantitative cut-offs required to make these claims under the FSC (for example, products that exceeded the $3 g$ of fat per $100 \mathrm{~g}$ required to make a low-fat claim). In terms of general-level health claims, which require stricter criteria to be followed by food manufacturers, nine of the 103 claims $(8.7 \%)$ were noncompliant, while 94 claims $(91.3 \%)$ were compliant with the code. Of the nine noncompliant general-level health claims, six $(66.7 \%)$ were classified as "general: not specified" and assessed as noncompliant as they were not a pre-approved claim under the FSC, nor a self-substantiated claim listed on the FSANZ website.

\section{Discussion}

This was the first study to assess the compliance of health, nutrition, and related claims in Australian yoghurt products since the revision of the FSC in 2013 [10]. A total of 340 different yoghurt products were found across the supermarkets audited, with $97.9 \%$ containing at least one identified claim. These findings are in contrast with previous Australian research conducted prior to the revision of the FSC, which found that only $30 \%$ 
of products carried health or nutrition claims [22], with most claims compliant with the FSC $(97.4 \%)$. In the present study, a total of 1680 health and nutrition claims were found across audited products. Of these, $93.9 \%$ of claims were classified as nutrition-content claims, with the remainder classified as general-level health claims. Most yoghurt products audited $(81.5 \%)$ met the nutrient profile scoring criterion (NPSC) and were thus considered to have a healthy nutrient profile, and eligible to carry health claims. Interestingly, this does not align with previous research into other food categories, which found higher proportions of products that did not meet the NPSC $[4,27,46]$.

The presence of health and nutrition claims on food packaging has rapidly expanded in the past decade [22] as the widening of permitted claims [10], and influence of claims on consumer purchasing behaviour $[47,48]$, has enticed food manufacturers to take advantage of this potential marketing method [2,47,49]. In the present study, $97.9 \%$ of yoghurt products audited contained a health, nutrition, or related claim, with an average of 5.0 claims per yoghurt product. These results exemplify the upward trend in claim prevalence, with previous studies noting substantially less yoghurt and dairy products carrying claims $(29-55 \%)[22,23,50]$. Similar results have been found for other food categories such as breakfast cereals [14,51], bakery products, and fruit and vegetable items [6,22]. Altogether, these findings reiterate the dynamic nature of the food environment, and the corresponding potential that food manufacturers see in using health and nutrition claims as a form of promotion and marketing. It is, therefore, imperative that policy developers and health professionals regularly monitor health messaging on product packaging to ensure that information is accurate and transparent for the consumer.

The revised FSC classifies health and nutrition claims into four categories: nutritioncontent claims, general-level health claims, high-level health claims, and therapeutic claims (which are not permitted to appear on food labels) [10]. Similar to previous audits of other food categories conducted in Australia [14,16,27], the most common claim type identified was nutrition-content claims (93.9\%), with a lower proportion of general-level health claims (6.1\%) (Table 5). Interestingly however, no high-level health claims or therapeutic claims were found during the audit, differing to findings seen in other food categories $[3,14,16,27]$.

Greater use of nutrition-content claims compared to general and high-level health claims has previously been reported and is speculated to be due to stricter criteria required to make health claims $[16,27,52,53]$. The reason for the absence of high-level claims in yoghurt products compared to other food categories may also be due to the varying nutrient profile of yoghurt products. For instance, it was observed that some varieties of plain yoghurt met the minimum quantity of calcium to make high-level health claims (related to calcium), whereas a flavoured variety by the same manufacturer did not contain the minimum quantity of calcium to make a claim. Therefore, if yoghurt manufacturers wanted to make high-level health claims on certain products, they would be required to have substantially different packaging for each flavour profile, which may not be physically and/or economically feasible.

Previous investigations have, however, seen the benefit in altering packaging to promote claims of this nature, with an Irish study noting that almost $16 \%$ of yoghurt products surveyed contained a high-level health claim [50]. Whilst claims of this nature must be accurate, the benefits $[54,55]$ and popularity of dairy yoghurt $[46,56]$ provide health professionals and manufacturers with an opportunity to use these claims to provide crucial health information to consumers. In all, while the absence of therapeutic claims suggests that the FSC is promoting safe and consumer-orientated practices in preventing the use of illegitimate claims [10], manufacturers should be encouraged to evaluate their products to ascertain whether higher-level claims are possible, in order to promote consumption of yoghurt as a core food.

Nutrition-content claims tend to encompass a range of food properties without as stringent criteria as other claim types, leading to a higher prevalence in the majority of food categories, including yoghurt (Table 5). The most common nutrition-content claim was "no artificial colours/flavours/preservatives" (Table 6), which was also found to be highly 
prevalent in audits of the claims on other food categories [14,27]. While the FSC outlines criteria for such claims [45], there is relatively limited regulation around factors such as the wording, colour, and position of nutrition-content claims which brings into doubt whether such claims are valuable for guiding consumer choice. It is therefore encouraged that enhanced regulation around the context and wording of nutrition-content claims be initiated to ensure marketing within the food industry does not come at the cost of transparent health information.

Claims, messaging, and advertising not included in any of the four categories outlined by the FSC, were classified as "puffery claims", which are vague and exaggerated claims that cannot be quantifiable [56] for example, "natural", and "boost your daily balance". While these claims are not included in the FSC, and so were not included for additional analysis in the present study, they were observed to be present in high prevalence in audited yoghurt products, further reinforcing the marketing techniques used by manufacturers to influence consumers. These findings support previous research relating to the high prevalence of marketing on food packaging [16]. Combined with the influence of claims on consumer food choices [47], it is clear that the presence of puffery claims may have significant consequences at the consumer and public health level. Such findings warrant direct consumer research into how puffery claims, and other marketing techniques are received and interpreted, and their impact on consumer expectations and decision making. Additionally, these results further the case for increased regulation around the marketing of food and beverage products, and challenge health professionals, such as dietitians, to accurately decipher and interpret this information in order to empower consumers to make health-conscious decisions.

The NPSC was applied to all products in order to assess whether they were allowed to carry a health claim (general-level or high-level health claim) [11]. Previous research exploring the use of the NPSC and HSR on Australian dairy products not only indicated a high level of agreement between products with a HSR greater than three and NPSC eligibility, but also that $74.0 \%$ of yoghurt products met the NPSC [46]. A slightly higher proportion of products meeting the NPSC was found in the current study $(n=277,81.5 \%)$; this slight increase may be due to differences in yoghurt products at the time of analysis (Sydney 2014 vs. Illawarra 2020), but overall, these findings reinforce the active response by yoghurt manufacturers to alter and reinvigorate products to adhere to nutrient profiling and enhance product appeal [57].

The importance of the NPSC in distinguishing "healthy" and "unhealthy" products was conveyed to varying extents in the current study. While it is important that healthy products are eligible to carry health claims, the NPSC also plays an important role in restricting less healthy products from carrying health-related claims. Although yoghurt is considered to be a core food [58], the ability of the NPSC to distinguish between products was illustrated in the present study when examining the results by product category. For instance, $72.2 \%$ of yoghurt products categorised as "yoghurt, flavoured or added fruit and/or cereal, high fat ( $>4 \mathrm{~g} / 100 \mathrm{~g}$ fat)" did not meet the NPSC (Table 7). The higher fat content in the majority of these products, and associated health complications related to elevated consumption of saturated fat $[59,60]$, emphasise the crucial role that the NPSC can play in creating a supportive food environment for consumers through minimising the presence of potentially influential health claims on unhealthy products.

Despite these benefits, nutrition profiling systems such as the NPSC have been criticised in the literature for their lack of specificity. For instance, in the current model, nutrient assessments and calculations are consistent across all food groups with the only distinction coming in the point-based categories to determine whether products can carry a health claim [61]. While this promotes uniformity and ease-of-use for consumers, some believe that nutrient profile criteria should be different for each core food group [62,63]. The separation of criteria could allow for greater transparency and consistency [62] of foods classified as "healthy" and "unhealthy" under the NPSC. For instance, while over 70\% of yoghurt products classified as "high fat" did not meet the NPSC, research suggests that higher dairy 
fat intake is not associated with the same cardiovascular risks as saturated fat in other foods $[64,65]$. Furthermore, the average saturated fat content per serving of dairy-yoghurt products analysed was only $2.8 \mathrm{~g}$, highlighting the minimal contribution such products make to consumers' total daily intake of saturated fat. In all, this emphasises that moving towards a food-group-specific profiling system may not only enhance the validity of the NPSC [62], but also shift focus from viewing foods purely based on their nutrients to a more holistic outlook on food, aligning with the concept of food synergy [66-68]. Overall, these findings, along with the lack of specificity in the current NPSC [61] invites re-examination of this nutrient profiling method to ensure that it correctly considers the health value of different foods.

Another form of nutrient profiling utilised by food manufacturers is the HSR. Introduced in 2014, this voluntary rating system was established to assist consumers make healthier food and beverage choices [69]. While this scheme is not recognised in the revised FSC [10], the increasing prevalence of this label on product packaging [70] and controversial uptake by consumers and manufacturers [71,72] justifies analysis and assessment into this prevailing component of the Australian food environment. In the current study, only a small proportion of yoghurt products $(12.1 \%)$ carried the HSR. While these findings are consistent with other studies of dairy products [70], the established link between the HSR and NPSC of most categories in promoting foods consistent with the Australian Dietary Guidelines (ADG) (e.g., foods considered "healthy" under the NPSC generally have higher HSR) $[46,63]$ brings into question why yoghurt manufacturers have not followed other food categories $[46,73,74]$ in using the HSR on product packaging. This presents the opportunity for future research to investigate this disparity and provide further clarification into HSR uptake and manufacturer perceptions of the rating system.

In addition, previous studies have shown that a vast majority of consumers see the HSR as an effective and easy-to-use method of quickly evaluating the "healthiness" of products [71]. Food manufacturers in certain food categories have increasingly utilised the HSR [70] in attempts to add appeal to their products, while also potentially promoting an effective means of prompting positive health choices within the food environment. Despite this, progress within this space has been uneven; as noted in the current study where yoghurt products displaying the HSR generally had higher ratings, which is consistent with findings in other food categories [70]. It is therefore recommended that policy developers and health professionals improve the reliability and accuracy of the HSR to be consistent across all food and beverage products, with mandatory HSR labelling required on all products regardless of the rating.

A crucial aspect required for consumers to navigate the food environment in a healthorientated manner is to ensure that health, nutrition, and related claims are accurate and consistent. This can be achieved through examining the compliance of such claims against relevant legislation, which in Australia is the FSC. Of all the health and nutrition claims analysed in the audit, 97.4\% were compliant with the revised FSC (Table 9). The high level of compliance seen in yoghurt claims is consistent with findings in previous audits $[14,16,27]$ of other food categories. This suggests that in the four years since enforcement of the revised FSC, manufacturers have continued to adapt and adhere to regulation regarding the use of health and nutrition claims on product packaging. The high rate of claim compliance among yoghurt products (Table 9) also highlights the effectiveness of the FSC in harnessing product labelling to support consumers to make informed health decisions in the food environment.

In terms of yoghurt categories assessed, the majority of claims in each category were compliant with the FSC (Table 9). Yoghurt products in the "children's yoghurt" category had the highest proportion of noncompliant claims (9.5\%); however, the small number of children's yoghurt products assessed $(n=19)$ must be considered when interpreting the data. Nonetheless, the high proportion of noncompliant claims in this category is of some concern, due to the influence of health messaging and marketing on children [16], and preference for "children"-labelled products by parents and carers [75]. Products 
in the "yoghurt, flavoured or added fruit, full fat" also had a substantial proportion of noncompliant claims $(n=13,8.1 \%)$ compared to other categories assessed. The presence of noncompliant claims in these categories could be due to a number of reasons, including misinformed marketing techniques, lack of awareness and understanding of the standards governing health and nutrition claims, as well as possibly an absence of product packaging reformulation prior to the revised FSC. It is therefore suggested that educational seminars in relation to the FSC should be targeted at food manufacturers, as misinformation [76] in combination with additional marketing techniques [2,47-49] can promote negative purchasing and health behaviour.

Finally, regarding claim-specific compliance, $97.8 \%$ of nutrition-content claims were compliant with the FSC; which, while providing a sense of reassurance, brings into question whether further research might be needed to ensure that these claims are being interpreted as anticipated, or whether revision of their use might be needed regarding the wording and/or marketing of such claims. Moreover, almost one in 10 general-level health claims were noncompliant with the code $(8.7 \%)$, with only one health claim appearing on a product that did not meet the NPSC. It is pleasing to note, however, that this proportion is substantially lower than findings in other food categories [14,16,27]. This difference may be due to the higher rate of self-substantiated claim compliance in the current study compared to others [14], emphasising manufacturers' successful utilisation of the protocol under Standard 1.2.7 to promote consumer confidence in a variety of health claims [77]. It is recommended, however, that a greater degree of evaluation and analysis by manufacturers, health professionals, and policy developers is undertaken regarding noncompliant claims and potentially problematic and influential areas such as the wording and requirements of health and nutrition claims. Overall, this will assist in promoting a health-conscious food environment in the absence of inaccurate, ambiguous, and misleading health and nutrition claims, further supporting consumers to make healthy food choices.

There are a number of limitations that should be considered when interpreting the results of this study. As this study only examined the health, nutrition, and related claims in Australian yoghurt products, results cannot be generalised to all food categories in the Australian food environment. In addition, as all five supermarkets surveyed were in the Illawarra region, future researchers are challenged to examine and assess yoghurt products in other regions of Australia, as availability may vary across locations [78]. This limitation was somewhat mitigated by the selection of supermarkets across a range of socio-economic areas [79], and the choice of supermarket type based on market share [28]. The included and excluded yoghurt products list for the audit (Table 1) was established using the AUSNUT 2011-13 Classification System [36] in conjunction with yoghurt products found in the targeted supermarket aisles (the "dairy" and/or "yoghurt" aisle) (see Methods). Of the 13 yoghurt categories included for analysis, only 10 were identified during the audit, which may have been due to unavailability at the time of surveying, products moved to other aisles of the supermarket and/or human error in category allocation. Future research may address these limitations by repeating the audit to include more supermarket aisles and stores. In addition, while nondairy yoghurts appeared within the targeted supermarket aisles, they were not outlined in the "yoghurt" category of the AUSNUT Classification System [36]. As these products were classified as "milk substitutes" and this study focused on dairy yoghurts, nondairy yoghurts were excluded from analysis. However, as these products are gaining traction and popularity among consumers [80], investigating the compliance of claims and consumer interpretation within this category in future research may be beneficial in further understanding the food environment.

Finally, it should be noted that as the FSC is not intended to be prescriptive, claim compliance and classification was at times ambiguous, and in such cases a second researcher was consulted (EN), and interpretations of the revised FSC were made. As such, it should be noted that findings may be categorised differently among other researchers, manufacturers, and regulators of the code. 


\section{Conclusions}

This study, which was the first to assess the compliance of health, nutrition, and related claims in Australian yoghurt products since the revision of the FSC in 2013, identified that dairy-yoghurt products had a high prevalence of claims $(n=1680)$, with nutrition-content claims the most common (93.9\%). Most claims assessed were compliant with the code $(97.4 \%)$, reinforcing manufacturers and policy developers' successful enforcement of the revised code. Although most claims were compliant, the greater proportion of noncompliant claims in the general-level health claims category shows the need for continued adaptation and monitoring by food businesses and authorities to ensure that health, nutrition, and related claims on product packaging are accurate, transparent, and understandable.

As a whole, the NPSC was a suitable profiling system in distinguishing "healthy" and "unhealthy" yoghurt products, with a high proportion of higher fat products unable to carry health claims. However, the inability of the NPSC to distinguish between food groups and/or categories despite varying evidence regarding the effect of nutrients in certain products, reinforces the need for nutrient profiling methods to adapt in order to remain relevant and effective. Moreover, the low proportion of yoghurt products carrying the HSR potentially underscores the consumer and manufacturer uncertainty in relation to the use and importance of this rating scheme. Nonetheless, the potential and increasing prevalence of the HSR among other food categories highlights how the HSR could be employed on yoghurt packaging to promote health-orientated practices and choices within the food environment.

Additional research into the various marketing techniques used by food manufacturers is warranted from findings in this study, as of the observed use of puffery claims indicates that this needs to be researched further to ensure these are not unduly influencing consumer behaviour. Furthermore, the ambiguity of wording and context of health, nutrition, and related claims challenges health professionals and policy developers to evaluate and bring in stricter measures to promote consistency in health messaging. Overall, through enhanced monitoring and collaboration between food manufacturers, policy developers and health professionals, health, nutrition, and related claims can be utilised to support the food industry in promoting health-orientated practices and food choices among consumers.

Supplementary Materials: The following are available online at https:/ /www.mdpi.com/article/10 $.3390 /$ nu13061835/s1, Figure S1: Flow chart of claims included and excluded within the revised FSC (derived from FSANZ Standard 1.2.7), Table S1: Nutrient Estimation Table (Fibre).

Author Contributions: Conceptualization, S.-R.S.W., E.P.N., A.T.M.; methodology, S.-R.S.W., E.P.N., A.T.M.; data analysis, S.-R.S.W., E.P.N.; writing—original draft preparation, S.-R.S.W.; writingreview and editing, E.P.N., A.T.M.; supervision, E.P.N., A.T.M. All authors have read and agreed to the published version of the manuscript.

Funding: This research received no external funding.

Institutional Review Board Statement: Not applicable.

Informed Consent Statement: Not applicable.

Data Availability Statement: The data presented in this study are available on request from the corresponding author.

Acknowledgments: The authors wish to acknowledge the store managers for granting permission for the audit to be conducted in their stores.

Conflicts of Interest: The authors declare no conflict of interest.

\section{References}

1. Miklavec, K.; Pravst, I.; Grunert, K.G.; Klopčič, M.; Pohar, J. The influence of health claims and nutritional composition on consumers' yoghurt preferences. Food Qual. Prefer. 2015, 43, 26-33. [CrossRef]

2. Van Camp, D.; de Souza Monteiro, D.M.; Hooker, N.H. Stop or go? How is the UK food industry responding to front-of-pack nutrition labels? Eur. Rev. Agric. Econ. 2012, 39, 821-842. [CrossRef] 
3. Tapsell, L.C. Evidence for health claims: A perspective from the Australia-New Zealand region. J. Nutr. 2008, 138, 1206S-1209S. [CrossRef] [PubMed]

4. Mhurchu, C.N.; Brown, R.; Jiang, Y.; Eyles, H.; Dunford, E.; Neal, B. Nutrient profile of 23,596 packaged supermarket foods and non-alcoholic beverages in Australia and New Zealand. Public Health Nutr. 2016, 19, 401-408. [CrossRef] [PubMed]

5. Harris, J.L.; Thompson, J.M.; Schwartz, M.B.; Brownell, K.D. Nutrition-related claims on children's cereals: What do they mean to parents and do they influence willingness to buy? Public Health Nutr. 2011, 14, 2207-2212. [CrossRef]

6. Al-Ani, H.H.; Devi, A.; Eyles, H.; Swinburn, B.; Vandevijvere, S. Nutrition and health claims on healthy and less-healthy packaged food products in New Zealand. Br. J. Nutr. 2016, 116, 1087-1094. [CrossRef]

7. Lartey, A.; Hemrich, G.; Amoroso, L. Influencing food environments for healthy diets. In Rome: Food and Agriculture Organization of the United Nations; FAO: Rome, Italy, 2016; pp. 43-75.

8. James, P.; Seward, M.W.; O'Malley, A.J.; Subramanian, S.; Block, J.P. Changes in the food environment over time: Examining 40 years of data in the Framingham Heart Study. Int. J. Behav. Nutr. Phys. Act. 2017, 14, 84. [CrossRef]

9. Bailey, M. Consumer profiles and behavior in Australian shopping centers. Chart 2013, 2, 1.

10. Food Standards Australia New Zealand. Australia and New Zealand Food Standards Code—Standard 1.2.7—Nutrition, Health and Related Claims. Canberra (AU): FSANZ. 2018. Available online: https:/ /www.legislation.gov.au/Details/F2017C01048 (accessed on 30 January 2020).

11. Department of Agriculture and Water Resources. Short Guide for Industry to the Nutrient Profiling Scoring Criterion in Standard 1.2.7-Nutrition, Health and Related Claims; Department of Agriculture and Water Resources: Canberra, Australia, 2016.

12. Riley, M.; Stonehouse, W. Food regulation: Substantiating health claims. Food Aust. 2016, 68, 22.

13. Lister, C. Fresh produce and new health claims regulations. Food N. Z. 2014, 14, 18.

14. Sussman, R.L.; McMahon, A.T.; Neale, E.P. An audit of the nutrition and health claims on breakfast cereals in supermarkets in the Illawarra region of Australia. Nutrients 2019, 11, 1604. [CrossRef] [PubMed]

15. Tong, T.; Rangan, A.; Gemming, L. Evaluating the nutritional content of children's breakfast cereals in Australia. Children 2018, 5, 84. [CrossRef] [PubMed]

16. Pulker, C.E.; Scott, J.A.; Pollard, C.M. Ultra-processed family foods in Australia: Nutrition claims, health claims and marketing techniques. Public Health Nutr. 2018, 21, 38-48. [CrossRef] [PubMed]

17. Department of Agriculture. Milk and Milk Products (Including Dairy by Defintion Products); Department of Agriculture: Canberra, Australia, 2014.

18. Lappe, J.M.; McMahon, D.J.; Laughlin, A.; Hanson, C.; Desmangles, J.C.; Begley, M.; Schwartz, M. The effect of increasing dairy calcium intake of adolescent girls on changes in body fat and weight. Am. J. Clin. Nutr. 2017, 105, 1046-1053. [CrossRef]

19. US Department of Health and Human Services. Calcium — Fact Sheet for Health Professionals; US Department of Health and Human Services: Washington, DC, USA, 2019. Available online: https://ods.od.nih.gov/factsheets/Calcium-HealthProfessional/\#en1 (accessed on 14 May 2020).

20. Pasiakos, S.M. Metabolic advantages of higher protein diets and benefits of dairy foods on weight management, glycemic regulation, and bone. J. Food Sci. 2015, 80, A2-A7. [CrossRef] [PubMed]

21. Merrilees, M.; Smart, E.; Gilchrist, N.; Frampton, C.; Turner, J.; Hooke, E.; March, R.; Maguire, P. Effects of dairy food supplements on bone mineral density in teenage girls. Eur. J. Nutr. 2000, 39, 256-262. [CrossRef] [PubMed]

22. Sobierajski, M.; Spratt, B.; Williams, P.; Houston, A.; Roesler, A.; Ridges, L.; Rafferty, J.; Yeatman, H.R. Nutrition function, health and related claims on packaged Australian food products-prevalence and compliance with regulations. Asia Pac. J. Clin. Nutr. 2006, 15, 10.

23. Dragicevich, H.; Williams, P.; Ridges, L. Survey of health claims for Australian foods made on Internet sites. Nutr. Diet. 2006, 63, 139-147. [CrossRef]

24. Kwon, K.I.; Park, S.H.; Lee, J.H.; Kim, J.Y.; Yoo, K.S.; Lee, J.S.; Kim, S.Y.; Sung, H.; Nam, H.S.; Kim, J.W. Prevalence of nutrition labeling and claims on processed, and packaged foods. Korean J. Community Nutr. 2007, 12, 206.

25. Ayoob, K.-T.; Duyff, R.L.; Quagliani, D. Position of the American Dietetic Association: Food and nutrition misinformation. J. Am. Diet. Assoc. 2002, 102, 260-266. [CrossRef]

26. Nestle, M.; Ludwig, D.S. Front-of-package food labels: Public health or propaganda? JAMA 2010, 303, 771-772. [CrossRef]

27. Hughes, J.; Neale, E.; McMahon, A. Exploring how nutrition information is used to guide healthy food choices in the food environment and dietetic practice. In School of Medicine and Health; University of Wollongong: Wollongong, NSW, Australia, 2019; p. 100.

28. Morgan, R. Woolworths and Aldi Grow Grocery Market Share in 2018; Tonic House: Melbourne, VIC, Australia, 2019; Volume 7936, pp. 1-3.

29. Australian Bureau of Statistics. Census of Population and Housing: Socio-Economic Indexes for Areas (SEIFA); ABS Cat. No. 2033.0.55.001; Australian Bureau of Statistics: Canberra, Australia, 2016. Available online: https:/ /www.abs.gov.au/ausstats/ abs@.nsf/Lookup/by\%20Subject/2033.0.55.001 \{\}2016 \{\}Main\%20Features \{\}IRSAD\%20Interactive\%20Map \{\}16 (accessed on 4 February 2020).

30. Nandi, A.; Glymour, M.M.; Subramanian, S. Association among socioeconomic status, health behaviors, and all-cause mortality in the United States. Epidemiology 2014, 25, 170-177. [CrossRef]

31. Mortimer, G. ALDI gives suppliers, as well as shoppers, greater choice: Retail expert. J. Home Econ. Inst. Aust. $2016,23,39$. 
32. Mortimer, G.; Grimmer, L. The Conversation. Available online: https://theconversation.com/love-them-or-loathe-them-privatelabel-products-are-taking-over-supermarket-shelves-98465 (accessed on 23 February 2020).

33. Coles Supermarket Australia Pty Ltd, 2020, Coles Online, Coles Supermarket Australia Pty Ltd. Available online: https: / / shop.coles.com.au/a/warrawong/home?cid=wsm (accessed on 14 June 2020).

34. Woolworths Group Limited, 2020, Woolworths Online, Woolworths Group Limited. Available online: https://www.woolworths com.au (accessed on 23 July 2020).

35. McCabe, T. ABC News. Available online: https://www.abc.net.au/news/2018-08-02/aldi-supermarket-coles-woolworths/1006 5018\#: \{\}:text=The\%20company\%20is\%20unlikely\%20to,particular\%20segment\%20of\%20the\%20market (accessed on 19 March 2020).

36. Food Standards Australia New Zealand. AUSNUT 2011-13 Food and Dietary Classification System; Food Standards Australia New Zealand: Canberra, Australia, 2013.

37. Carey, C. INFANT (Guidelines 4, 13.1). 2014. Available online: https:/ / resus.org.au/glossary/infant-guidelines-4-13-1/ (accessed on 24 March 2020).

38. Zohrabi, M. Mixed Method Research: Instruments, Validity, Reliability and Reporting Findings. Theory Pract. Lang. Stud. 2013, 3, 254-262. [CrossRef]

39. Hughes, C.; Wellard, L.; Lin, J.; Suen, K.L.; Chapman, K. Regulating health claims on food labels using nutrient profiling: What will the proposed standard mean in the Australian supermarket? Public Health Nutr. 2013, 16, 2154-2161. [CrossRef] [PubMed]

40. Food Standards Australia New Zealand, 2015, Ingredients List; FSANZ: Canberra, Australia, 2015. Available online: https://www. foodstandards.gov.au/consumer/labelling/ingredients/Pages/default.aspx (accessed on 23 March 2020).

41. Food Standards Australia New Zealand, 2016, Fruit and Vegetable Points (V Points); FSANZ: Canberra, Australia, 2016. Available online: https://www.foodstandards.gov.au/industry/labelling/Pages/Fruit-and-Vegetable-points-(V-points).aspx (accessed on 14 March 2020).

42. Grafenauer, S.; Curtain, F. An audit of Australian bread with a focus on loaf breads and whole grain. Nutrients 2018, 10, 1106. [CrossRef] [PubMed]

43. Food Standards Australia New Zealand. Notified Food-Health Relationships to Make a Health Claim; FSANZ: Canberra, Australia 2020. Available online: https:/ / www.foodstandards.gov.au/industry/labelling/fhr/Pages/default.aspx (accessed on 4 March 2020).

44. Parker, G.; Frith, R. Health Star Rating System: Campaign Evaluation Report, 2016; Health Star Rating: Surry Hills, NSW, Australia, 2020.

45. Food Standards Australia New Zealand (2016) Australia New Zealand Food Standards Code-Schedule 4-Nutrition, Health and Related Claims; FSANZ: Canberra, Australia, 2018. Available online: https:/ / www.legislation.gov.au/Details/F2017C00711 (accessed on 30 January 2020).

46. Wellard, L.; Hughes, C.; Watson, W.L. Investigating nutrient profiling and Health Star Ratings on core dairy products in Australia. Public Health Nutr. 2016, 19, 2860-2865. [CrossRef]

47. Dixon, H.; Scully, M.; Niven, P.; Kelly, B.; Chapman, K.; Donovan, R.; Martin, J.; Baur, L.A.; Crawford, D.; Wakefield, M. Effects of nutrient content claims, sports celebrity endorsements and premium offers on pre-adolescent children's food preferences: Experimental research. Pediatric Obes. 2014, 9, e47-e57. [CrossRef]

48. Ares, G.; Giménez, A.; Bruzzone, F.; Vidal, L.; Antúnez, L.; Maiche, A. Consumer visual processing of food labels: Results from an eye-tracking study. J. Sens. Stud. 2013, 28, 138-153. [CrossRef]

49. Williams, P. Consumer understanding and use of health claims for foods. Nutr. Rev. 2005, 63, 256-264. [CrossRef]

50. Lalor, F.; Kennedy, J.; Flynn, M.A.; Wall, P.G. A study of nutrition and health claims-a snapshot of what's on the Irish market. Public Health Nutr. 2010, 13, 704-711. [CrossRef]

51. Devi, A.; Eyles, H.; Rayner, M.; Mhurchu, C.N.; Swinburn, B.; Lonsdale-Cooper, E.; Vandevijvere, S. Nutritional quality, labelling and promotion of breakfast cereals on the New Zealand market. Appetite 2014, 81, 253-260. [CrossRef] [PubMed]

52. Franco-Arellano, B.; Bernstein, J.T.; Norsen, S.; Schermel, A.; L'Abbé, M.R. Assessing nutrition and other claims on food labels: A repeated cross-sectional analysis of the Canadian food supply. BMC Nutr. 2017, 3, 74. [CrossRef] [PubMed]

53. Bursey, A.S.; Wiles, N.L.; Biggs, C. The nutrient quality and labelling of ready-to-eat snack foods with health and/or nutrition claims. S. Afr. J. Clin. Nutr. 2019. [CrossRef]

54. Roy Morgan. Roy Morgan. Available online: http://www.roymorgan.com/findings/8011-australian-yoghurt-market-march-20 19-201906070624\#: \{\}:text=Natural\%20or\%20plain\%20varieties\%20of,conducted\%20by\%20Roy\%20Morgan\%20in (accessed on 5 April 2020).

55. Curtain, F.; Grafenauer, S. Comprehensive nutrition review of grain-based muesli bars in Australia: An audit of supermarket products. Foods 2019, 8, 370. [CrossRef] [PubMed]

56. Simons, T. The Amazing Study! The Effect of Puffery in Advertisement Claims on Perceived Credibility, Perceived Truthfulness, Attitude, and Purchase Intentions of Dutch and American Consumers; University of Twente: Enschede, The Netherlands, 2017.

57. Pothoulaki, M.; Chryssochoidis, G. Health claims: Consumers' matters. J. Funct. Foods 2009, 1, 222-228. [CrossRef]

58. National Health and Medical Research Council. Australian Guide to Healthy Eating. Available online: https://www.eatforhealth gov.au/sites/default/files/content/The\%20Guidelines/n55a_australian_dietary_guidelines_summary_131014_1.pdf (accessed on 4 June 2020). 
59. Mozaffarian, D.; Hao, T.; Rimm, E.B.; Willett, W.C.; Hu, F.B. Changes in diet and lifestyle and long-term weight gain in women and men. N. Engl. J. Med. 2011, 364, 2392-2404. [CrossRef]

60. Micha, R.; Mozaffarian, D. Saturated fat and cardiometabolic risk factors, coronary heart disease, stroke, and diabetes: A fresh look at the evidence. Lipids 2010, 45, 893-905. [CrossRef]

61. Food Standards Australia New Zealand (2016) Australia New Zealand Food Standards Code-Schedule 5-Nutrient Profiling Scoring Method. FSANZ: Canberra, Australia, 2018. Available online: https://www.legislation.gov.au/Details/F2015L00475 (accessed on 28 January 2020).

62. Cooper, S.L.; Pelly, F.E.; Lowe, J.B. Construct and criterion-related validation of nutrient profiling models: A systematic review of the literature. Appetite 2016, 100, 26-40. [CrossRef]

63. Dunford, E.K.; Huang, L.; Peters, S.A.; Crino, M.; Neal, B.C.; Ni Mhurchu, C. Evaluation of alignment between the health claims nutrient profiling scoring criterion (NPSC) and the Health Star Rating (HSR) nutrient profiling models. Nutrients 2018, 10, 1065. [CrossRef]

64. Liang, J.; Zhou, Q.; Amakye, W.K.; Su, Y.; Zhang, Z. Biomarkers of dairy fat intake and risk of cardiovascular disease: A systematic review and meta analysis of prospective studies. Crit. Rev. Food Sci. Nutr. 2018, 58, 1122-1130. [CrossRef]

65. National Heart Foundation of Australia. Heart Healthy Eating Patterns; National Heart Foundation of Australia: Canberra, Australia, 2019; Available online: https://www.heartfoundation.org.au/getmedia/c6836ea5-a5fc-454c-a257-5988ec89f8d1 /Nutrition_Position_Statement_-_HHEP_FINAL-3.pdf (accessed on 14 May 2020).

66. Jacobs, D.R.; Tapsell, L.C. Food, not nutrients, is the fundamental unit in nutrition. Nutr. Rev. 2007, 65, 439-450. [CrossRef]

67. Jacobs, D.R.; Tapsell, L.C. Food synergy: The key to a healthy diet. Proc. Nutr. Soc. 2013, 72, 200-206. [CrossRef]

68. Jacobs, D.R., Jr.; Gross, M.D.; Tapsell, L.C. Food synergy: An operational concept for understanding nutrition. Am. J. Clin. Nutr. 2009, 89, 1543S-1548S. [CrossRef] [PubMed]

69. Health Star Rating, 2020, Health Star Rating System, HSR, Canberra, Australia. Available online: http://www.healthstarrating. gov.au/internet/healthstarrating/publishing.nsf/content/home (accessed on 4 May 2020).

70. Jones, A.; Shahid, M.; Neal, B. Uptake of Australia's health star rating system. Nutrients 2018, 10, 997. [CrossRef] [PubMed]

71. Parker, G.; Souvlis, P.; Parry-Husbands, H. Health Star Rating System: Consumer Use and Understanding; Pollinate Research: Surry Hills, NSW, Australia, 2015.

72. Hamlin, R.; McNeill, L. Does the Australasian "health star rating" front of pack nutritional label system work? Nutrients 2016, 8, 327. [CrossRef] [PubMed]

73. Peters, S.A.; Dunford, E.; Jones, A.; Mhurchu, C.N.; Crino, M.; Taylor, F.; Woodward, M.; Neal, B. Incorporating added sugar improves the performance of the health star rating front-of-pack labelling system in Australia. Nutrients 2017, 9, 701. [CrossRef]

74. Carrad, A.M.; Louie, J.C.Y.; Yeatman, H.R.; Dunford, E.K.; Neal, B.C.; Flood, V.M. A nutrient profiling assessment of packaged foods using two star-based front-of-pack labels. Public Health Nutr. 2016, 19, 2165-2174. [CrossRef]

75. Abrams, K.M.; Evans, C.; Duff, B.R. Ignorance is bliss. How parents of preschool children make sense of front-of-package visuals and claims on food. Appetite 2015, 87, 20-29. [CrossRef]

76. García, A.L.; Morillo-Santander, G.; Parrett, A.; Mutoro, A.N. Confused health and nutrition claims in food marketing to children could adversely affect food choice and increase risk of obesity. Arch. Dis. Child. 2019, 104, 541-546. [CrossRef]

77. Wellard-Cole, L.; Watson, W.L.; Hughes, C.; Chapman, K. How effective is food industry self-substantiation of food-health relationships underpinning health claims on food labels in Australia? Public Health Nutr. 2019, 22, 1686-1695. [CrossRef] [PubMed]

78. Woolworths Groups Limited, Frequently Asked Questions, 2020. Woolworths Group Limited. Available online: https://www. woolworths.com.au/shop/discover/shopping-online/finding-products-on-woolworths (accessed on 25 August 2020).

79. Morland, K.; Wing, S.; Roux, A.D. The contextual effect of the local food environment on residents' diets: The atherosclerosis risk in communities study. Am. J. Public Health 2002, 92, 1761-1768. [CrossRef] [PubMed]

80. Bansal, S.; Mangal, M.; Sharma, S.K.; Gupta, R.K. Non-dairy based probiotics: A healthy treat for intestine. Crit. Rev. Food Sci. Nutr. 2016, 56, 1856-1867. [CrossRef] [PubMed] 